\begin{tabular}{|c|l|}
\hline Title & Pall ladium-Catalyzed Benzylic C-H Borylation of A lky lbenzenes with Bis(pinacolato)diboron or Pinacol borane. \\
\hline Author(s) & Ishiyama, Tatsuo; Ishida, Kousaku; Takagi, Jun; Miy aura, Norio \\
\hline Citation & Chemistry Letters, 30(11), 1082-1083 \\
\hline Issue Date & 2001-11-05 \\
\hline Doc URL & http://hdl.handle.net/2115/56194 \\
\hline Type & article (author version) \\
\hline File Information & (26) B-B + H-Benzyl (Com).pdf \\
\hline
\end{tabular}

Instructions for use 


\section{Palladium-catalyzed Benzylic C-H Borylation of Alkylbenzenes with Bis(pinacolato)diboron or Pinacolborane}

Tatsuo Ishiyama,* Kousaku Ishida, Jun Takagi, and Norio Miyaura*

Division of Molecular Chemistry, Graduate School of Engineering, Hokkaido University, Sapporo 060-8628

(Received July 19, 2001; CL-010679)

Borylation at the benzylic $\mathrm{C}-\mathrm{H}$ bond of alkylbenzenes with bis(pinacolato)diboron $\quad\left[\left(\mathrm{Me}_{4} \mathrm{C}_{2} \mathrm{O}_{2}\right) \mathrm{B}-\mathrm{B}\left(\mathrm{O}_{2} \mathrm{C}_{2} \mathrm{Me}_{4}\right)\right]$ or pinacolborane $\left[\left(\mathrm{Me}_{4} \mathrm{C}_{2} \mathrm{O}_{2}\right) \mathrm{B}-\mathrm{H}\right]$ was carried out at $100{ }^{\circ} \mathrm{C}$ in the presence of a catalytic amount of $10 \% \mathrm{Pd} / \mathrm{C}$. The reaction selectively afforded pinacol benzylboronates in good yields directly from various alkylbenzenes.

The transition metal-catalyzed $\mathrm{C}-\mathrm{C}$ and $\mathrm{C}-\mathrm{X}$ bond formation accompanied with activation of inactive $\mathrm{C}-\mathrm{H}$ bonds has emerged as an interesting and important alternative to the conventional bond-forming reactions involving functionalized substrates. ${ }^{1}$ Since organoboron compounds are versatile intermediates in organic synthesis, ${ }^{2}$ an extension of the methodology to borylation reactions would have significant synthetic value. Indeed, several pioneering studies have been made on the coupling reactions of bis(pinacolato)diboron (1) or pinacolborane (2). The direct borylation of alkanes and benzene with the diboron 1 was catalyzed by $\mathrm{Cp} * \operatorname{Re}(\mathrm{CO})_{3}$ under photochemical conditions ${ }^{3}$ or by $\mathrm{Cp} * \mathrm{Rh}\left(\eta^{4}-\mathrm{C}_{6} \mathrm{Me}_{6}\right)$ under thermal conditions. ${ }^{4}$ The latter complex, ${ }^{5}$ $\mathrm{Cp} * \operatorname{Ir}\left(\mathrm{PMe}_{3}\right)(\mathrm{H})\left[\mathrm{B}\left(\mathrm{O}_{2} \mathrm{C}_{2} \mathrm{Me}_{4}\right)\right],{ }^{5,6}$ and $\left(\mathrm{Cp}^{*} \mathrm{RhCl}_{2}\right)_{2}{ }^{7}$ have been successfully used for aromatic $\mathrm{C}-\mathrm{H}$ borylation with pinacolborane 2, and $\mathrm{RhCl}\left[\mathrm{P}(i-\mathrm{Pr})_{3}\right]_{2}\left(\mathrm{~N}_{2}\right)^{7}$ for benzylic $\mathrm{C}-\mathrm{H}$ borylation. In the course of our studies on the transition metal-catalyzed reactions of diboron compounds, ${ }^{8}$ we recently found that $\mathrm{Pd} / \mathrm{C}$ is an efficient catalyst for selective benzylic $\mathrm{C}-\mathrm{H}$ borylation of alkylbenzenes (3) with the diboron $\mathbf{1}$ or pinacolborane $\mathbf{2}$ to produce the corresponding pinacol benzylboronates (4) in good yields (eq 1). ${ }^{9}$

The borylation of toluene $(60$ mmol $)$ with 
bis(pinacolato)diboron $1(1.0 \mathrm{mmol})$ was carried out at $100{ }^{\circ} \mathrm{C}$ for $16 \mathrm{~h}$ in the presence of various metal complexes $(3 \mathrm{~mol} \%)$ to optimize the catalyst system. $\mathrm{Pd}(\mathrm{OAc})_{2}$ and $\mathrm{PdCl}_{2}$ produced pinacol benzylboronate as the sole product in $11 \%$ and $33 \%$ yields, respectively. In contrast, $\mathrm{NiCl}_{2}, \mathrm{PtCl}_{2}(\mathrm{COD}), \mathrm{RhCl}_{3}, \mathrm{IrCl}_{3}$, and $\mathrm{RuCl}_{3}$ exhibited no catalytic activity at all. Instantaneous formation of palladium black observed for $\mathrm{Pd}(\mathrm{OAc})_{2}$ and $\mathrm{PdCl}_{2}$ prompted us to use ligands; however, the addition of $\mathrm{PPh}_{3}$, $\mathrm{P}(c-\mathrm{Hex})_{3}, \mathrm{P}(\mathrm{OPh})_{3}, \mathrm{AsPh}_{3}$, and $\mathrm{SbPh}_{3}$ completely retarded the reaction, thus suggesting the superiority of ligand-free metallic palladium. Although commercial palladium black did not catalyze the reaction, a palladium on carbon $(10 \% \mathrm{Pd} / \mathrm{C})$ finally achieved the selective coupling in high yields. Very interestingly, two boryl groups in 1 participated in the reaction to provide $74 \%$ yield of the product based on the boron atom. ${ }^{10}$ Other heterogeneous catalysts such as $\mathrm{Pt} / \mathrm{C}, \mathrm{Rh} / \mathrm{C}$, and $\mathrm{Ru} / \mathrm{C}$ were totally ineffective.

In order to obtain further information on the formation of two moles of benzylboronate from one mole of the diboron, the $\mathrm{Pd} / \mathrm{C}$-catalyzed reaction of $\mathbf{1}$ with toluene at $100{ }^{\circ} \mathrm{C}$ was followed by $\mathrm{GC}$ analysis. The diboron was completely consumed after $2.5 \mathrm{~h}$, but the yield of benzylboronate was $49 \%$. Further prolongation of the reaction time increased the yield even after the complete consumption of the diboron. Finally, the reaction gave $74 \%$ yield of benzylboronate after $9 \mathrm{~h}$. The results indicated a two-step process involving a very fast and quantitative reaction of toluene with the diboron 1 followed by a slow reaction with pinacolborane $\mathbf{2}$ generated by the former process. A $52 \%$ yield of pinacol benzylboronate was obtained indeed when pinacolborane was treated with toluene at $100{ }^{\circ} \mathrm{C}$ in the presence of $\mathrm{Pd} / \mathrm{C}(3 \mathrm{~mol} \%){ }^{10}$

The representative results are summarized in Table 1. All reactions of bis(pinacolato)diboron $\mathbf{1}$ or pinacolborane $\mathbf{2}$ were carried out at $100{ }^{\circ} \mathrm{C}$ in the presence of $10 \% \mathrm{Pd} / \mathrm{C}(3-6 \mathrm{~mol} \%) .{ }^{10}$ Not only toluene (Entry 1), but also polymethylated benzenes are viable substrates. $o^{-}, m^{-}$, and $p$-Xylenes smoothly underwent the selective monoborylation to provide the corresponding benzylboronates 4 in good yields in the presence of $3 \mathrm{~mol} \%$ catalyst (Entries 2-4), while mesitylene required $6 \mathrm{~mol} \%$ of catalyst to achieve a satisfactory yield (Entry 5). Ethylbenzene yielded a 3:1 mixture of the benzylboronate and the homobenzyl derivative. The latter product can be derived from positional isomerization of the benzylpalladium intermediate to a homobenzylpalladium species via the $\beta$-hydride elimination-insertion process (Entry 6). ${ }^{11}$ Another probable pathway involving a direct $\mathrm{C}-\mathrm{H}$ activation at the $\beta$-carbon 
should be ruled out by the fact that no reaction was observed for tert-butylbenzene. Isopropylbenzene exclusively afforded the homobenzyl derivative due to large steric hindrance at the benzylic carbon (Entry 7). On the other hand, the borylation of 4-isopropyltoluene selectively occurred at the methyl group, though the reaction was accompanied with a small amount of 2-(4-methylphenyl)-1-propylboronate (Entry 8). In all reactions, the diboron 1 gave higher yields than pinacolborane 2 .

In contrast to the results of unfunctionalized alkylbenzenes, the reaction was highly sensitive to the presence of heteroatoms. For example, 4-methylanisole and 4-fluorotoluene resulted in $13 \%$ and $26 \%$ yields, respectively, even at higher catalyst loading or prolongation of reaction time. All attempts at the borylation of 4-methylacetophenone, 2-methylthiophene, and 2-methylfuran were unsuccessful.

In conclusion, $\mathrm{Pd} / \mathrm{C}$ was found to be an efficient catalyst for the selective benzylic $\mathrm{C}-\mathrm{H}$ borylation of alkylbenzenes with bis(pinacolato)diboron and pinacolborane. The method provides a simple and direct route for the synthesis of benzylboronic esters which have been prepared via transmetalation between benzylmagnesium halide and trialkyl borate. The catalytic direct borylation of other hydrocarbons is being actively investigated.

\section{References and Notes}

\# Dedicated to Prof. Hideki Sakurai on the occasion of his 70th birthday.

1 For recent reviews, see: a) G. Dyker, Angew. Chem., Int . Ed., 38, 1698 (1999). b) Y. Guari, S. Sabo-Etienne, and B. Chaudret, Eur. J. Inorg. Chem., 1999, 1047. c) S. S. Stahl, J. A. Labinger, and J. E. Bercaw, Angew. Chem., Int. Ed., 37, 2180 (1998).

2 a) A. Pelter, K. Smith, and H. C. Brown, Borane Reagents; Academic, London (1988). b) D. S. Matteson, Stereodirected Synthesis with Organoboranes; Springer, Berlin (1995).

3 H. Chen and J. F. Hartwig, Angew. Chem., Int. Ed., 38, 3391 (1999).

4 H. Chen, S. Schlecht, T. C. Semple, and J. F. Hartwig, Science, 287, 1995 (2000).

5 J.-Y. Cho, C. N. Iverson, and M. R. Smith, III, J. Am. Chem. Soc., 122, 12868 (2000).

6 C. N. Iverson and M. R. Smith, III, J. Am. Chem. Soc., 121, 7696 (1999).

7 During the course of our study, the rhodium-catalyzed benzylic $\mathrm{C}-\mathrm{H}$ borylation with pinacolborane was appeared in: S. Shimada, A. S. Batsanov, J. A. K. Howard, and T. B. 
Marder, Angew. Chem., Int. Ed., 40, 2168 (2001).

8 T. Ishiyama and N. Miyaura, J. Organomet. Chem., 611, 392 (2000).

9 K. Ishida, J. Takagi, T. Ishiyama, N. Miyaura, and J. F. Hartwig, 79th Annual Meeting of Chemical Society of Japan, Kobe, March 2001, Abstr., No. 1H439.

10 A representative procedure for 4 : To $10 \% \mathrm{Pd} / \mathrm{C}(0.03 \mathrm{mmol})$ were successively added toluene $(60 \mathrm{mmol})$ and $\mathbf{1}$ or $2(1.0$ $\mathrm{mmol}$ ), and the resulting mixture was stirred at $100{ }^{\circ} \mathrm{C}$ for 16 $\mathrm{h}$ under nitrogen. The product was extracted with benzene, washed with water, and dried over $\mathrm{MgSO}_{4}$. Filtration and Kugelrohr distillation gave analytically pure pinacol benzylboronate: ${ }^{1} \mathrm{H}$ NMR (400 MHz, $\mathrm{CDCl}_{3}$ ) $\delta 1.23$ (s, 12 $\mathrm{H}), 2.29$ (s, $2 \mathrm{H}), 7.1-7.3(\mathrm{~m}, 5 \mathrm{H}) ;{ }^{13} \mathrm{C} \mathrm{NMR}(100 \mathrm{MHz}$, $\mathrm{CDCl}_{3}$ ) $\delta 24.69,83.38,124.79,128.22,128.96,138.61$ (Due to quadrupolar relaxation, the carbon attached to the boron atom was not detected); HRMS $m / z$ Found: $\mathrm{M}^{+}, 218.1470$. Calcd for $\mathrm{C}_{13} \mathrm{H}_{19} \mathrm{BO}_{2}: 218.1478$.

11 S. Siegel, in "Comprehensive Organic Synthesis," ed. by B. M. Trost, Pergamon, Oxford (1991), Vol. 8, Chap. 3.1, p. 417. 


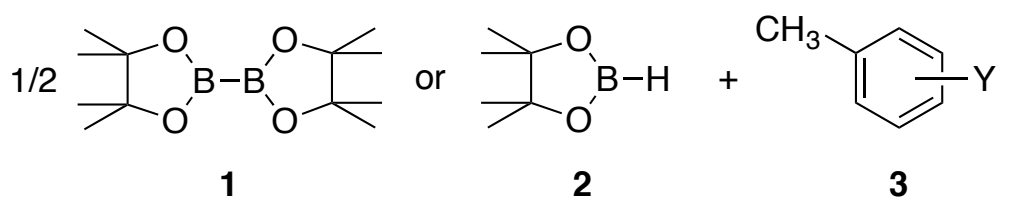

$\underset{100{ }^{\circ} \mathrm{C}}{10 \% \mathrm{Pd} / \mathrm{C}} \underset{\mathrm{O}^{\prime}}{\mathrm{B}} \overbrace{\frac{\mathrm{Y}}{\mathrm{C}}}^{\mathrm{O}}+1 / 2 \mathrm{H}_{2}$ or $\mathrm{H}_{2}$ 
Table 1. Synthesis of Pinacol Benzylboronates via Direct Benzylic C-H Borylation (eq 1) ${ }^{\mathrm{a}}$

Yield/\% $\%^{\mathrm{c}}$

aThe experimental procedure, see Reference $10 .{ }^{b}$ The pinB abbreviates 4,4,5,5-tetramethyl-1,3,2-dioxaboryl group. ${ }^{\text {G }}$ GLC yields based on boron atom in $\mathbf{1}$ or $2 .{ }^{\mathrm{d}} \mathrm{A} 6 \mathrm{~mol} \%$ of catalyst was used. 